\title{
The effect of a physical activity program on chronic psychiatric patients' positive and negative symptoms and depression levels: A randomized controlled trial
}

\author{
Neslihan LOK, Kerime BADEMLI, Sefa LOK
}

Faculty of Health Sciences, Selçuk University, Konya, Turkey.

Faculty of Nursing, Akdeniz University, Antalya, Turkey.

Faculty of Sport Sciences, Selçuk University, Konya, Turkey.

Address correspondence to N. Lok, e-mail: neslihanlok1@gmail.com

\begin{abstract}
Physical activity is widely recognized as an important behavioral means of risk prevention and illness management, or alternatively, recovery and the realization of well-being. Mental health nurses have a holistic approach to the health care of those with mental illness and physical activity is an important component of holistic care. This research was undertaken in order to analyze the effect a physical activity program has on positive and negative symptoms of patients with schizophrenia and their depression levels. This is a randomly controlled experimental study designed with a pre-test and posttest. The Scale for the Assessment of Positive Symptoms, the Scale for the Assessment of Negative Symptoms and the Calgary Depression Scale for Schizophrenia were used in this research. The study was carried out with 60 patients, 30 in the experimental and 30 in the control group. The Mann-Whitney U and Wilcoxon tests were used, and the Cronbach's alpha coefficient was calculated. It was found that there was a significant difference between the mean scores on the Scale for the Assessment of Positive Symptoms and the Scale for the Assessment of Negative Symptoms $(\mathrm{p}<0.05$.) According to this study's findings, the physical activity program for patients with schizophrenic had a statistically significant positive effect on their positive and negative symptoms and depression levels. As a results; 1 ) this randomized-controlled trial investigated the effect of physical activity program on positive and negative symptoms depression levels among of patients with schizophrenia, 2) results of this study on 60 patients with schizophrenia showed that an 12-week group physical activity program was significantly effective in patients with schizophrenia' positive and negative symptoms depression, 3) physical activity should be routinely included in plans of psychiatric nursing care.
\end{abstract}

Key words: Chronic psychiatric patients, depression, physical activity.

\section{INTRODUCTION}

Schizophrenia is a chronic mental illness, chronic mental illnesses adversely affect the emotions, thoughts, perceptions and behavior of an individual. Schizophrenia negatively impact the lives of the patients (34). Schizophrenia includes positive and negative symptomatology (29). Negative symptoms may cause people with schizophrenia to be disinterested in physical activity (38). Decreased physical activities worsen the metabolisms of patients with schizophrenia (40). Previous research demonstrated that patients with schizophrenia who exhibit limited physical activity, that the amount of time they spend sitting is higher than average and increased body mass index as a consequence of result of sedentary life style (35). Furthermore, psychotropic drugs' side effects increase the risk of obesity in of patients with schizophrenia (34). Therefore physical activity should be included among nursing practices in the care of patients with schizophrenia (19). Physical activity is widely recognized as an important behavioral means of risk prevention and illness management, or alternatively, recovery and the realization of well-being. Mental health nurses are positive regarding the potential benefits of physical activity to the patient and approximately half support physical activity as a component of their role $(33,19)$.

Studies dealing with the relation between mental illness and physical activity state that physical activity helps physical health, increases quality of life, enhances cognitive functions, improves moods and is effective in healing the 
symptoms of depression and psychotic disorders $(5,18,26,30,33)$. In a study severity of schizophrenia symptoms and neurocognitive deficits are associated with lower levels of physical activity (25). Depression in particular is highly prevalent among patients with schizophrenia (21). There is evidence that physical activity reduces depressive symptoms in patients with schizophrenia (13, $30,33,38,39$ ). A systematic review and a metaanalysis that examined the effectiveness of physical activity in patients with a schizophrenia spectrum disorder also reported that physical activity were effective in improving clinical symptoms, quality of life, functioning, and depressive symptoms in patients with schizophrenia (8). In a study that analyzed the effectiveness of an six-minute walking distance program showed that the program reduced patients with schizophrenia mean scores associated with body fat and greater reductions on positive and negative syndrome scale scores but this finding were not statistically significant (3). In a systematic review conducted by Farholm \& Sørensen, 2016 (12) stated that studies about physical activity among patients with schizophrenia are still relatively small but it is developing rapidly over the last decade. However randomized controlled studies that examine the effect of physical activity on positive and negative symptoms are limited (2).

Mental health nurses have a holistic approach to the health care of those with mental illness and physical activity is an important component of holistic care. In a study conducted by Happell et al. (18) stated that psychiatric nurses thought that physical and mental health was a whole and physical activity was part of holistic care. Nevertheless the emphasis on physical activity in general is not reflected in mental health nurses research, practice, or mental health care (19). Nurses in psychiatry clinics are responsible for such intervention programs as taking protective measures for physical illnesses, early diagnosis, exercise and diet along with developing healthy behavior (9). Going beyond the routine treatments that are widely used in the treatment of schizophrenia and are in most cases limited to drug therapy and supportive psychotherapy, it is very important to develop new intervention methods and to determine their clinical and social benefits. Although physical activity for patients with schizophrenia has proven to be beneficial for them, it is not among the routine practices. In a study conducted by Cullen, \& McCann, (7) stated that, physical activity provided benefits for patient with schizophrenia in terms of physical and mental health including social inclusion and engagement, which can enhance quality of life and recovery. Physical activity does have a positive role in treatments of patients with schizophrenia (7). There is no planned physical activity program in Turkey for schizophrenic patients. Therefore, physical activity programs should be established and become widespread across the country, thereby contributing to patients with schizophrenia rehabilitation processes and improving their quality of life. Due to the fact that studies on the effect physical activity has on positive and negative symptoms and depression levels of patients with schizophrenia are not accessible in our country, this work is aimed at meeting the need for developing a physical activity program for schizophrenic patients and determining its activity.

\section{Hypotheses}

Hypothesis 1: There will be a significant difference between the Calgary Depression Scale for schizophrenia mean score of the patients who participate in the physical activity program and the mean score of the control group.

Hypothesis 2: The mean score on the Scale for the Assessment of Positive Symptoms of those patients who participate in the physical activity will be lower than the mean score of the control group.

Hypothesis 3: The mean score on the Scale for the Assessment of Negative Symptoms of the patients who participate in the physical activity will be lower than the mean score of the control group.

\section{MATERIALS \& METHODS}

\section{Setting, Design and Sample}

The research is a randomly controlled experimental study designed with a pre-test and post-test. The research took place at the Center for Public Mental Wellbeing affiliated with the Konya Training and Research Hospital. The 136 schizophrenic patients over eighteen years old who are registered at the Center for Public Mental Wellbeing affiliated with the Konya Training and Research Hospital constituted the population of the research. In the calculation of the sample size of the research, 0.75 influence quantity (Cohen d) (11), 0.80 power, and 0.05 type 1 error margin were postulated, and the sample size was calculated to be 46. Because the possibility that samples may be loss 
the sample size for the study was 60, with 30 subjects each in the experimental and the control groups.

Inclusion criteria of the study were that participants must consent to participate in the study, be literate and above 18 years of age, and be the registered at the Center for Public Mental Wellbeing and must have score 11 or above on the Calgary Depression Scale for Schizophrenia. Exclusion criteria were to attend less than two sessions of exercise, attending a similar accompanying program and being younger than 18 years old.

Patients with schizophrenia who agreed to participate in the trial were selected randomly with simple randomization. The participants were assigned to physical activity and control groups. http://www.randomizer.org/form.htm was used for this. The files of 136 people with schizophrenia were evaluated by the researcher in accordance with the criteria for inclusion in or exclusion from the sample and 69 names were put into the randomization process (Figure 1). In terms of socio-demographic characteristics, gender, marital status and education level showed no statistically significant differences between physical activity and control group.

The physical activity group was divided three groups and each groups were attended separately on Monday, Thursday, Wednesday and Sunday. Participants were enrolled in groups according to the times that suited to them. Each group was consisting of ten participants. The physical activity and control group, 30 participants completed the program.

\section{Measurements}

A questionnaire about socio-demographic information of the individuals, the Scales for the Assessment of Positive and Negative Symptoms and the Calgary Depression Scale for Schizophrenia were used in the data collection process. In order to evaluate the clarity of the questions, a pilot test took place for six patients who are registered at the Center for Mental Wellbeing before the collection of the data. The data collected from the participants in the pilot test are not included in the research.

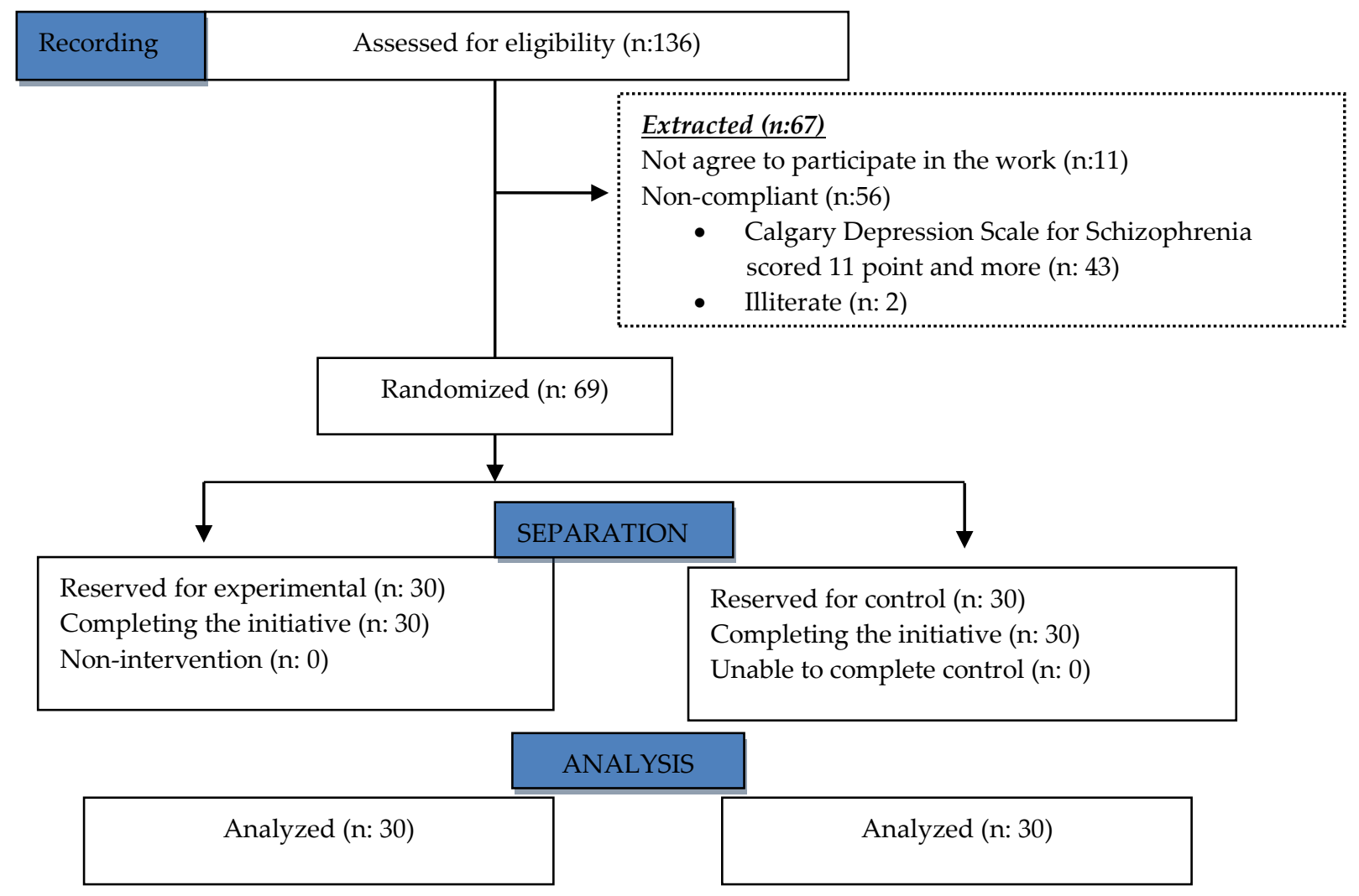

(References:http://www.consort-statement.org/Media/Default/Downloads/Translations/Turkish_tr/Turkish\%20CONSORT\%20 Flow\%20Diagram.pdf)

Figure 1. CONSORT Schema 
Positive Symptoms Scale (SAPS): The Scale for the Assessment of Positive Symptoms has four subscales and 35 items. These sub-scales are hallucinations, delusions, vagaries and formal thought disorders. Items 1-7 belong to hallucinations, $8-20$ to delusions, 21-25 to vagaries and 26-34 to formal thought disorders. The scale is a sestet Likert type scale. Scores for each item vary between 0-5. Total scores range from 0-120. Adding up the sub-scale item scores yields sub-scale total scores, and adding up the sub-scale total scores yields the total scale score. In the validity and reliability study of the Turkish form of the scale, a cutoff score was not calculated. The reliability study of the Turkish form has been done (10).

Negative Symptoms Scale (SANS): It consists of five sub-scales and 24 items. The subscales are applanation or affective blunting, alogia, apathy, anhedonia and lack of attention. Items 1-7 belong to the affective blunting sub-scale, 8-12 to alogia, 13-16 to apathy, 17-21 to anhedonia and 22-24 to lack of attention. Total scores range from 0-120. The reliability study of the Turkish form has been done (10).

The Calgary Depression Scale for Schizophrenia: This scale was developed by Addington et al. (1992). The validity and reliability study of the scale was done by Aydemir et al. (1) with schizophrenic patients. The scale is one that the interviewer evaluates, and I consist of nine questions that are evaluated as a four-point Likert type scale. Each item is scored between 0-3, and totals scores range from 0-27. The items include depressive mood, hopelessness, a sense of worthlessness; resentment related to guilt, pathological guiltiness, morning depression, early awakening, suicide and observed symptoms of depression. When developing the scale, it was intended not to let it be affected by positive and negative symptoms and extrapyramidal side effects, and there are studies showing that it is capable of measuring depression independent from these effects. The cutoff score the Turkish version of the scale was determined to be 11 or 12. In this study, the cutoff score was 11. Higher scores mean higher levels of depression.

\section{Data Collection}

The data was collected from schizophrenic patients registered at the Beyhekim Center for Public Mental Wellbeing of the Konya Training and Research Hospital. The research began after the ethical agreement and institutional permission were received. The data for the pre-test and posttest of the physical activity and control groups were collected in the center's meeting room in interviews the researcher held with the patients.

\section{Intervention}

\section{Development of the Physical Activity Program}

Before the study was implemented among patients with schizophrenia, content of the program was designed in line with the relevant literature $(5,18,29,39)$. We sought expert opinions from four faculty members in the psychiatric nurse department and sports health department. The program was finalized after corrections. The program was consisting of 12 sessions.

\section{Implementation of the Physical Activity Program}

Before implementing the program Positive Symptoms Scale, Negative Symptoms Scale and The Calgary Depression Scale for Schizophrenia were applied to the physical activity and the control group. Patients with schizophrenia in the physical activity group were provided program by the psychiatric nurse and associate professor in sports health science. The physical activity program was completed in 12 week with each group participated 35 minute a day on the designed day. Twice a week (Mondays and Thursdays) the patients in the physical activity group were helped to warm up for five minutes and then performed exercises that lasted 30 minutes and included 22 simple movements, which included attention and coordination in order to maximize their capacity of learning and memorizing. These were followed by five minutes of cooling movements. The other two days (Wednesdays and Saturdays) the patients were helped to perform five minutes of warm up and 30 minutes of walking followed by five minutes of cooling down movements. In the final month, the time of main exercise increased to 40 minutes, although the five minutes of warm up and five minutes of cooling down remained the same.

During the implementation of the physical activity program, psychiatric nurse had pre sessions meetings with patients. During each session psychiatric nurse performed physical activity with the patients. During each session associate professor in sports health science showed activities. At the end of the physical activity program Positive Symptoms Scale, Negative Symptoms Scale and The Calgary Depression Scale for Schizophrenia were applied to both physical activity and the control group. 
Following to interventions process, the physical activity program was applied to the control group.

\section{Data Analysis}

The statistics of the data analysis of the study were evaluated with SPSS 18.0 software. For the descriptive statics of the data analyses of the study. In the evaluation of the data analysis, numbers, percentages, means and standard deviations were evaluated. The Mann-Whitney $U$ test was used for the individual groups, to compare the corresponding scale scores of the physical activity and control groups. Wilcoxon method was used for data with a normal distribution. The Cronbach's alpha coefficients were calculated for the scale and its sub dimensions' reliability.

\section{Ethical Procedure}

The study protocol was approved by the Ethical Board for Clinical Research of the Medical School at Selcuk University. All participants were given information about the name, aim, length and type of the research, and each read the agreement form. Informed voluntary consent was obtained from all participants. Data collection and the implementation were initiated after agreement was provided.

\section{RESULTS}

Comparing the data regarding the individuals' socio-demographic features found no statistical significance between the physical activity and control groups ( $\mathrm{p}>0.05$; Table 1$)$.

\section{Comparison of the Depression Levels in the physical activity group and control group}

The mean depression score of the physical activity group decreased after the intervention (after 12 weeks) in comparison to their mean depression score prior to the intervention (day zero), and this difference was statistically significant $(p<0.05)$. The mean depression score of the control group decreased after the intervention in comparison to the mean score pre intervention, but this difference was statistically insignificant ( $p>0.05)$. Pre intervention (day zero) there was no significant difference between the mean depression scores of the physical activity group and the control group, the measurement after the intervention indicated that the mean depression score of the physical activity group was lower than that of the control group, and this difference was statistically significant $(\mathrm{p}<0.05$; Table 2$)$.

Table 1. Comparison of the individuals' socio-demographic characteristics.

\begin{tabular}{|c|c|c|c|c|c|}
\hline \multirow{2}{*}{$\begin{array}{l}\text { Socio-demographic } \\
\text { Characteristics }\end{array}$} & \multicolumn{2}{|c|}{$\begin{array}{l}\text { Experimental group } \\
(\mathrm{n}: 30)\end{array}$} & \multicolumn{2}{|c|}{$\begin{array}{l}\text { Control group } \\
(\mathrm{n}: 30)\end{array}$} & \multirow[t]{2}{*}{$\mathrm{P}$} \\
\hline & $\mathrm{n}$ & $\%$ & $\mathrm{n}$ & $\%$ & \\
\hline \multicolumn{6}{|l|}{ Gender } \\
\hline Female & 17 & 56.7 & 14 & 40.0 & 0.38 \\
\hline Male & 13 & 43.3 & 16 & 60.0 & \\
\hline \multicolumn{6}{|l|}{ Marital Status } \\
\hline Married & 9 & 30.0 & 6 & 20.0 & 0.74 \\
\hline Single & 10 & 33.3 & 14 & 46.7 & \\
\hline Divorced & 11 & 36.7 & 10 & 33.3 & \\
\hline \multicolumn{6}{|l|}{ Education } \\
\hline Primary/secondary school & 14 & 46.7 & 16 & 53.3 & 0.64 \\
\hline High School & 16 & 53.3 & 14 & 46.7 & \\
\hline \multicolumn{6}{|l|}{ Social Insurance } \\
\hline & 21 & 69.9 & 11 & 36.6 & 0.76 \\
\hline Yes & 9 & 30.1 & 19 & 63.4 & \\
\hline \multicolumn{6}{|l|}{ No } \\
\hline & \multicolumn{2}{|c|}{ Experimental group } & \multicolumn{2}{|c|}{ Control group } & $\mathrm{P}$ \\
\hline & \multicolumn{2}{|c|}{ Mean \pm SD } & \multicolumn{2}{|c|}{ Mean \pm SD } & \\
\hline Age & \multicolumn{2}{|c|}{$40.76 \pm 7.96$} & \multicolumn{2}{|c|}{$38.67 \pm 8.19$} & 0.53 \\
\hline
\end{tabular}


Table 2. Comparing the patients' mean Calgary Depression Scale for schizophrenia scores with the pre- and post-test results $($ Mean \pm SD).

\begin{tabular}{lcccc}
\hline CDSS & Experimental Group & Control Group & $\mathrm{U}$ & $\mathrm{p}$ \\
\hline Baseline & $16.26 \pm 2.31$ & $17.70 \pm 2.47$ & 7.500 & 0.17 \\
Post intervention & $10.93 \pm 2.71$ & $16.96 \pm 2.09$ & 2.750 & $0.001^{*}$ \\
Test value & $\mathrm{Z}: 2.306$ & $\mathrm{Z}: 2.174$ & & \\
$\mathrm{P}$ & $0.015^{*}$ & 0.21 & & \\
\hline
\end{tabular}

$\mathrm{Z}=$ Wilcoxon analysis, $\mathrm{df}($ degrees of freedom $)=2,{ }^{*} \mathrm{p}<.05$

\section{Comparison of the Positive Symptoms in the} physical activity group and control group

The study determined that the mean scores of the individuals in the physical activity group on the positive symptoms scale reduced at the end of the intervention process (after 12 weeks) in comparison to the pre- intervention scores (day 0). The difference between the scores was statistically significant $(\mathrm{p}<0.05)$. The mean scores of the participants in the control group on the positive symptoms scale also reduced at the end of the intervention compared to the pre intervention phase, and the difference between the scores was not statistically significant $(\mathrm{p}>0.05)$. Even though there was no statistically significant difference between positive symptoms scale mean scores of the physical activity and control groups before the intervention (day 0), the measurement that was conducted after the intervention (at the end of 12 weeks) indicated that the positive symptoms scale mean score of the physical activity group was lower than that of the control group, and the difference between them was statistically significant $(\mathrm{p}<0.05$; Table 3$)$.

Table 3. Comparing the patients' Positive Symptoms Scale mean scores with pre- and post-test results (Mean \pm SD).

\begin{tabular}{lcccc}
\hline Positive Symptoms Scale & Experimental Group & Control Group & $\mathrm{U}$ & $\mathrm{p}$ \\
\hline Baseline & $12.93 \pm 1.96$ & $12.50 \pm 2.22$ & 0.457 & 0.27 \\
Post-intervention & $10.66 \pm 1.74$ & $12.46 \pm 1.43$ & 0.635 & $0.001^{*}$ \\
Test value & $\mathrm{t}: 0.694$ & $\mathrm{t}: 0.754$ & & \\
$\mathrm{P}$ & $0.001^{*}$ & 0.22 & & \\
\hline
\end{tabular}

$\mathrm{t}$ : $\mathrm{t}$ test, $\mathrm{df}$ (degree of freedom): $2,{ }^{*} \mathrm{p}<.05$

Table 4. Comparing the Patients' Mean Negative Symptoms Scale Scores with the Preand Post-test Results (Mean \pm SD).

\begin{tabular}{lcccc}
\hline Negative Symptoms Scale & Experimental Group & Control Group & $\mathrm{U}$ & $\mathrm{p}$ \\
\hline Baseline & $20.53 \pm 3.12$ & $19.66 \pm 3.02$ & 0.750 & 0.12 \\
Post intervention & $14.36 \pm 1.88$ & $18.90 \pm 3.78$ & 0.500 & $0.001^{*}$ \\
Test value & $\mathrm{t}: 0.055$ & $\mathrm{t}: 19.477$ & & \\
$\mathrm{p}$ & $0.018^{*}$ & 0.76 & \\
\hline
\end{tabular}

$\mathrm{t}$ : t test, df (degrees of freedom): $2{ }^{*} \mathrm{p}<.05$ 
Comparison of the negative symptoms in the physical activity group and control group

Significant differences were found between the pre intervention and post intervention, negative symptoms scale mean score of the physical activity group whereas there were no significant differences between the negative symptoms scale mean score of the control group over the post intervention measurements. The mean score of negative symptoms scale of the control group decreased after the intervention in comparison to their mean score prior to the intervention and this difference was statistically significant ( $p>0.05$; Table 4 ).

\section{DISCUSSION}

This study's findings demonstrate that the physical activity program had significant positive effects on the positive and negative symptoms and the depression of the patient with schizophrenia. In a randomized controlled trial suggest some benefits of activity for psychiatric symptom management (29). In a meta-analysis study evaluates the effect of physical activity in patients with schizophrenia and states that physical activity has positive effects on functionality, clinical symptoms and depression levels (8). Although in a study it is stated that In respect of lasting improvements in positive and negative symptoms there is no change in psychiatric symptoms (15). The length of the studies and the intensity of the physical activity level might affect. This can be attributed content, length and orderly implementation of the physical activity program. In the literature, the duration of these interventions also varies: some lasting only 8 weeks (21), while others went on for 18 months (28). This study's physical activity program was implemented four times a week for three months. On Mondays and Thursdays, the patients were helped to warm up for five minutes and then performed exercises each of which lasted 30 minutes and included 22 simple movements, which included attention and coordination in order to maximize their capacity for learning and memorizing. These were followed by five minutes of cooling down movements. The other two days (Wednesdays and Saturdays) patients were helped to perform five minutes of warm up and 30 minutes of walking followed by five minutes of cooling down movements. In the final month, the duration of the main exercise was increased to 40 minutes, although the five minutes of warm up and five minutes of cooling down remained the same. The program's positive effects on the depressive symptoms and positive and negative symptoms of the schizophrenic patients may have been due to the fact that the exercises were performed on a regular basis and their length. Studies of the effects exercise programs have on schizophrenic patients $(4,21,32)$ report that the performance of exercise on a regular basis and its type and length has positive effects on patients. In a qualitative study in which the effectiveness of physical activity was assessed, patient with schizophrenia also stated that they benefited from physical activity (15). Considering these positive effects of physical activity on the symptoms of schizophrenic patients, nurses can provide physical activity is included in daily mental health care (19). In the present study provide support for our hypotheses that depressive symptoms of patients with schizophrenia are associated with physical activity. Physical activity program had significant positive effects on the depression of the patient with schizophrenia. Although Cochrane review stated that physical activity is insufficient evidence for continuous improvement of depressive symptoms (27), there is some evidence that physical activity reduces depressive symptoms in patients with schizophrenia $(12,29,32,37)$. Leutwyler et al. (24) also reported that greater severity of depressed symptoms of patient with schizophrenia was associated with more time spent in sedentary activity. Further evidence suggests that physical activity as a treatment for depression and that concluded that physical activity led to a greater reduction in depressive symptoms (23). Besides this the outcomes of numerous trials investigating the effect of physical activity on schizophrenia have led to the inclusion of physical activity recommendations in the treatment guidelines (35). Mental health nurses may perform an important role in encouraging physical activity and legitimizing its incorporation within care planning (13). That contribute positively to regular physical activity, symptoms of schizophrenia and depression can cause significant improvements when used in combination with other pharmacological and psychosocial treatment in patients with schizophrenia. However, it is not again evident that research into physical activity, exercise and mental health is not readily accessible for these participants, nor has dissemination of such findings to these participants taken place in Turkey.

This study is limited to registered schizophrenic patients in the Beyhekim Center for Public Mental Wellbeing affiliated with the Konya Training and Research Hospital who were open to 
communication, had no issues with talking and agreed to participate in the study.

In conclusion, the physical activity program developed by this study had a positive effect on the positive and negative symptoms and depression levels of schizophrenic patients. Since physical activity training characteristics (e.g., frequency, intensity and duration) may play a critical role in determining outcomes, future studies should characterize physical activity interventions in detail so as to allow for their comparison. Mental health nurses, in cooperation with patients and other members of the team, can provide that physical activity is included in routinely mental health care. Nurses can improve the physical activity for patients with schizophrenia by encouraging patients and mental health facilities to incorporate physical activity into their daily routines. Regular physical activity programs that contribute to the rehabilitation process of patients with schizophrenia should be established and disseminated across the country.

\section{REFERENCES}

1. Aydemir Ö, Danacı A, Deveci A. Calgary Sizofrenide Depresyon Ölçeği'nin Türkçe versiyonunun güvenilirliği ve geçerliliği. Nöropsikiyatri Arsivi, 2000; 37: 82-86. (in Turkish).

2. Bassilios B, Judd F, Pattison P, Nicholas A, Moeller-Saxone K Predictors of exercise in individuals with schizophrenia: A test of the transtheoretical model of behavior change. Clinical Schizophrenia and Related Psychoses, 2015; 8: 173-182A.

3. Beebe LH, Tian L, Morris N, Goodwin A, Allen SS, Kuldau J. Effects of consequence, or trans-diagnostic issue? Schizophrenia Bulletin, 2005; 43(2): 240-244.

4. Bredin SSD, Darren ERW, Donna JL. The health benefits and challenges of exercise training in persons living with schizophrenia: a pilot study. Brain sciences, (2013); 2(3): 821848 .

5. Cankorur VS. Ruhsal Bozukluklar ve Fiziksel Aktivite: Depresyon, Anksiyete Bozuklukları, Affektif Bozukluklar, Yeme Bozuklukları, Madde Kullanım Bozuklukları ve Sizofreni, Korunma ve Tedavide Fiziksel Aktivitenin Rolü. Turkiye Klinikleri Journal of Sports Medicine-Special Topics, 2016; 2(2): 20-26. (in Turkish).

6. Chen LJ, Steptoe A, Chung MS, Ku PW. Association between actigraphyderived physical activity and cognitive performance in patients with schizophrenia. Psychological Medicine, 2016; 46(11): 2375-2384.

7. Cullen C, McCann E. Exploring the role of physical activity for people diagnosed with serious mental illness in Ireland. Journal of psychiatric and mental health nursing, 2015; 22(1): 58-64.

8. Dauwan M, Begemann MJ, Heringa SM, Sommer IE. Exercise improves clinical symptoms, quality of life, global functioning, and depression in schizophrenia: a systematic review and meta-analysis. Schizophrenia Bulletin, 2016; 42(3): 588-599.

9. Edward K, Rasmussen, Munro L. Nursing care of clients treated with atypical antipsychotics who have a risk of developing metabolic instability and/or type 2 diabetes. Archives of Psychiatric Nursing, 2010; 24(1): 46-53.

10. Erkoç S, Arkonaç O, Ataklı C. Negatif semptomlari değerlendirme ölçeğinin güvenilirliği ve geçerliliği. Düsünen Adam, 1991; 4: 20-24. (in Turkish).

11. Falkai P, Malchow B, Wobrock T, Gruber O, Schmitt, A, Honer WG, Cannon TD. The effect of aerobic exercise on cortical architecture in patients with chronic schizophrenia: a randomized controlled MRI study. European Archives of Psychiatry and Clinical Neuroscience, 2013; 263(6): 469-473.

12. Farholm A, Sørensen M. Motivation for physical activity and exercise in severe mental illness: A systematic review of cross-sectional studies. International Journal Of Mental Health Nursing, 2016; 25(2): 116-126.

13. Faulkner G, Biddle S. Mental health nursing and the promotion of physical activity. Journal of Psychiatric and Mental Health Nursing, 2002; 9(6): 659-665.

14. Firth J, Cotter J, Elliott R, French P, Yung AR. A systematic review and metaanalysis of exercise interventions in schizophrenia patients. Psychological Medicine, 2015; 45(07): 1343-1361.

15. Fogarty M, Happell B. Exploring the benefits of an exercise program for people with schizophrenia: a qualitative study. Issues in Mental Health Nursing, 2005; 26(3): 341-351.

16. Forsberg KA, Björkman T, Sandman PO, Sandlund M. Influence of a lifestyle intervention among persons with a psychiatric disability: a cluster randomised controlled trail on symptoms, quality of life and sense of coherence. Journal of Clinical Nursing, 2010; 19(11-12): 1519- 1528.

17. Fraser SJ, Brown WJ, Whiteford HA, Burton NW. Impact of nurse-led behavioural counselling to improve metabolic health and physical activity among adults with mental illness. International Journal of Mental Health Nursing, doi: 10.1111/inm.12343 (2017)

18. Happell B, Platania-Phung C, Scott D. Placing physical activity in mental health care: A leadership role for mental health nurses. International Journal of Mental Health Nursing, 2011; 20(5): 310-318.

19. Happell B, Scott D, Platania-Phung C, Nankivell J. Nurses' views on physical activity for people with serious mental illness. Mental Health and Physical Activity, 2012; 5(1): 4-12.

20. Hausmann A, Fleischhacker WW. Differential diagnosis of depressed mood in patients with schizophrenia: a diagnostic algorithm based on a review. Acta Psychiatrica Scandinavica, 2002; 106(2): 83-96.

21. Heggelund J, Morken G, Helgerud J, Nilsberg GE, Hoff J. Therapeutic effects of maximal strength training on walking efficiency in patients with schizophrenia - a pilot study. Consequence, or trans-diagnostic issue? Schizophrenia Bulletin, 2012; 43(2): 240-244.

22. Heggelund J, Nilsberg GE, Hoff J, Morken G, Helgerud J.Effects of high aerobic intensity training in patients with schizophrenia: a controlled trial. Nordic Journal of Psychiatry, 2011; 65: 269-275. 
23. Lawlor DA, Hopker SW. The effectiveness of exercise as an intervention in the management of depression: systematic review and meta-regression analysis of randomised controlled trials. BMJ, 2001; 322(7289): 763.

24. Leutwyler H, Hubbard EM, Jeste DV, Miller B, Vinogradov S. Associations of schizophrenia symptoms and neurocognition with physical activity in older adults with schizophrenia. Biological Research for Nursing, 2014; 16(1): 23-30.

25. Lök S, Lök N. Kronik Psikiyatri Hastalarına Uygulanan Fiziksel Egsersiz Programlarının Etkinliği: Sistematik Derleme. Current Approaches in Psychiatry/Psikiyatride Guncel Yaklasimlar, 2016; 8(4): 354-366.

26. Mason OJ, Holt R. Mental health and physical activity interventions: a review of training in persons living with schizophrenia: a pilot study. Brain Sciences 2012; 3: 821-848.

27. Öyekçin, DG. Bir grup sizofreni ve sizoaffektif bozukluk hastasında metabolik sendrom sıklığı. Anadolu Psikiyatri Dergisi, 2009; 10(1): 26-33.

28. Poulin MJ, Chaput JP, Simard V, Vincent P, Bernier J, Gauthier Y, Lanctot G, Saindon J, Vincent A, Gagnon S, Tremblay A. Management of antipsychotic-induced weight gain: prospective naturalistic study of the effectiveness of a supervised exercise programme. Australian \& New Zealand Journal of Psychiatry, 2007; 41: 980-989.

29. Richardson CR, Faulkner G, McDevitt J, Skrinar GS, Hutchinson DS, Piette JD. Integrating physical activity into mental health services for persons with serious mental illness. Psychiatric Services, 2005; 56(3): 324-331.

30. Rosenbaum S, Tiedemann A, Sherrington C, Curtis J, Ward PB. Physical activity interventions for people with mental illness: a systematic review and meta-analysis. The Journal of Clinical Psychiatry, 2014; 75(9): 964-974.
31. Saunders JC. Families living with severe mental illness: A literature review. Issues in Mental Health Nursing, 2003; 24(2): 175-198.

32. Scheewe TW, Backx FJG, Takken T, Jörg F, Strater AV, Kroes AG, Cahn W. Exercise therapy improves mental and physical health in schizophrenia: a randomised controlled trial. Acta Psychiatrica Scandinavica, 2013; 127(6): 464-473.

33. Siris SG, Addington D, Azorin JM, Fallon IRH, Gerlach J, Hirsch SR. Depression in Schizophrenia: Recognition and Management in the USA. Schizophrenia Research, 2001; 47(23): 185-197.

34. Soundy A, Wampers M, Probst M, De Hert M, Stubbs B, Vancampfort D, Ströhle A. Physical activity and sedentary behaviour in outpatients with schizophrenia: A systematic review and meta-analysis. International Journal of Therapy \& Rehabilitation, 2013; 20(12): 588-596.

35. Stanton R. Happell B, Reaburn P. The mental health benefits of regular physical activity, and its role in preventing future depressive illness. Nursing: Research and Reviews, 2014; 4: 45-53.

36. Upthegrove R, Marwaha S, Birchwood M. Depression and schizophrenia: cause, the qualitative literature. Journal of Mental Health, 2017; 21(3): 274-284.

37. Vancampfort D, Probs M, Scheewe T, Knapen J, De Herdt A, De Hert $M$. The functional exercise capacity is correlated with global functioning in patients with schizophrenia. Acta Psychiatrica Scandinavica, 2012; 125(5): 382-387.

38. Vancampfort D, Sweers K, Probst M, Maurissen K, Knapen J, Minguet P, De Hert M. Association of the metabolic syndrome with physical activity performance in patients with schizophrenia. Diabetes \& Metabolism, 2011; 37(4): 318-323.

39. Zhu S, St-Onge MP, Heshka S, Heymsfield SB. Lifestyle behaviors associated with lower risk of having the metabolic syndrome. Metabolism, 2004; 53(11): 1503-1511. 